\title{
Attitudes towards tobacco consumption among healthcare professionals in a tertiary referral centre in Pakistan
}

\begin{abstract}
Background: The healthcare professionals (HPs) can play a pivotal role in tobacco cessation

Programs in any society. The HPs are often regarded as a role model for the community in developing nations like Pakistan. Ironically the smoking HPs may be a hindrance in the success of such programs. Little literature exits on the prevalence of tobacco consumption among HPs in Pakistan.
\end{abstract}

Aim: To establish the prevalence of tobacco consumption among HPs in a tertiary referral centre in

Pakistan.

Methods: A cross sectional study using a questionnaire with or without interviews of the participants. A total of 200 HPs were approached and were invited to participate voluntarily. The data was collected and analysed using SPSS.

Results : A total of 152 questionnaires were completed (response rate $=76 \%$ ), which included male

doctors $(n=24)$, female doctors $(n=14)$, nursing staff $(n=80)$ and paramedics $(n=34)$. Male respondents totaled $70(46 \%)$ whilst $82(53.9 \%)$ were females. Overall smoking rate was $14.5 \%$. However no female participants smoked; $33.8 \%$ of male physicians and $30.4 \%$ of male paramedics were current smokers. Health education and higher cost of cigarettes were regarded as the most effective anti-smoking strategies.

Conclusion: There is a significant trend of tobacco consumption in the form of smoking among male

HPs. It would seem logical to address smoking among HPs s that they can play an effective role in smoking cessation programs.

Keywords: tobacco consumption, healthcare professionals, gender differences, tobacco control strategies
Volume 2 Issue I - 2015

\author{
Jawad A,' Schultz ASH, ${ }^{2}$ Shahid O, ${ }^{3}$ Shakeel \\ $M,{ }^{4}$ Chaudhry MA ${ }^{3}$ \\ 'Department of Otorhinolaryngology, Aberdeen Royal Infirmary, \\ UK \\ ${ }^{2}$ Faculty of Nursing, University of Manitoba, Canada \\ ${ }^{3} \mathrm{CMH}$ Lahore Medical College, Lahore Cantt, Pakistan \\ ${ }^{4}$ Specialist Registrar Otolaryngology-head and neck surgery, \\ Aberdeen Royal Infirmary, UK
}

Correspondence: Ahsin Jawad, Department of Otorhinolaryngology, Aberdeen Royal Infirmary, 18 Middlefield Terrace, Aberdeen AB24 4PJ, UK, Tel +447908228800, Email ahsin.jawad@nhs.net

Received: December 30, 2014 | Published: January 15, 2015
Abbreviations: HPs, healthcare professionals; WHO, world health organization; FCTC, framework convention for tobacco control; $\mathrm{CMH}$, combined military hospital

\section{Introduction}

Tobacco consumption amongst the health professionals (HPs) has long been recognized as being an addictive habit with its associated side effects. On a global scale, smoking is the leading cause of preventable mortality and is associated with an estimated 5million deaths worldwide. ${ }^{1}$ Though traditionally considered to be a problem of wealthier nations, today global strategies focus on the increasing prevalence of smoking amongst developing countries. The World Health Organization (WHO) estimated in its 2009 report on the global tobacco epidemic that if smoking were to follow its current trends, then by the year 2030 more than 8 million people will lose their lives on an annual basis. ${ }^{2}$ What's even more alarming is that $70 \%$ of those deaths are predicted to occur in low to middle income countries. ${ }^{3}$ Health professionals especially doctors are considered important part of society in terms of health care, which can include idealization of their beliefs and habits. ${ }^{4}$ This study investigated the views, rates and gender differences in tobacco consumption among health professionals in Pakistan and their views on tobacco control including smoke free environments.

The various remarkable health effects associated with tobacco consumption, which lead to significant preventable morbidity and mortality ${ }^{5-7}$ supported the WHO in creating the Framework Convention for Tobacco Control ${ }^{8}$ (FCTC) to support countries in addressing this health priority. In 1995, the FCTC was ratified by 165 member countries and this document identifies 13 strategies (Articles 6-18) for member countries to adopt to reduce tobacco consumption. The strategies included the implementation of high taxes and restricting the importation of duty-free cigarettes along with the implementation of smoking cessation programs especially at educational and health institutes. ${ }^{8}$ WHO has also directed national health and education programs to include diagnosis and treatment of tobacco dependence and provision of counseling services with the participation of health, community and social workers. 8 Pakistan was one of the 165 original ratifying member countries. Current reported rates of tobacco consumption in Pakistani males and females are $34.5 \%$ and $6.2 \%$ respectively; ${ }^{9}$ these rates have remained unchanged for the last 5 years. ${ }^{10}$ 
Researchers in the Asia's have investigated medical students' behaviors and beliefs concerning tobacco consumption and control. A recent survey (2009-2010) of final year undergraduate medical students in Malaysia, India, Pakistan, Nepal, and Bangladesh reported a rate of current smokers as 13.1 and ever smokers $31.7 \%$ $(n=922)$. Half of them agreed that major changes in the curriculum are needed about the teaching of tobacco cessation strategies; they felt unprepared to effectively address patient tobacco dependence. ${ }^{11}$ Other studies of medical students attending Colleges in Pakistan, report rates of smoking in 2004-05 at $11.2 \%(\mathrm{n}=1029),{ }^{12}$ and in 2009 at $13.45 \%(n=654) .{ }^{13}$ Smoking rates are reported to be higher among male students and students smoke to relax along with being addicted to nicotine. It was common for students to have started smoking in their teens prior to entering medical school and peer influences were guiding this habit. Although rates vary, it is clear that health professional students are entering their educational programs addictive to nicotine.

In Pakistan, recently three studies focused on health professionals tobacco consumption rates and perspectives. In 2004, house physicians in Karachi were surveyed $(\mathrm{n}=200)$ and $32 \%$ reported being smokers. About half indicated starting smoking in their twenties and another $44 \%$ started in their teens; the majority stated peer influence for their initiation. Almost all indicated they smoke during duty hours. ${ }^{14}$ Next in 2006 , health professionals working at a tertiary hospital in Rawalpindi were surveyed $(n=300)$. Reported smoking rate was $28 \%$. Age of initiation for the majority of smokers was between 20-30 years; peer and family influences were cited as reasons for starting smoking. ${ }^{15}$ Finally, a 2009 survey of Lahore health professionals $(n=441)$ reported a smoking rate among doctors as $37.18 \%$ and $35.74 \%$ of paramedics. Rates of smoking by gender demonstrated significantly more males than females for both professions smoked; reflective of national general population rates. ${ }^{9,10}$ Most smokers started smoking prior to the age of 20 and peer pressure was the most common reason for this. These health professionals smoked for relaxation and due to addiction. ${ }^{16}$ In summary, it appears that about one-third of health professionals in these Pakistan health institutions consume tobacco, with males reporting higher rates, most started smoking prior to entering their profession and commonly ongoing smoking is for relaxation and being addicted.

\section{Methods}

A cross sectional survey of health professionals at Combined Military Hospital (CMH), Lahore Pakistan was conducted between July to October 2010. CMH is an Army administered tertiary care hospital with 1000 inpatient bed capacity and outpatient health care services available to Army and Civilian patients. As well, $\mathrm{CMH}$ is a teaching hospital for a variety of health professional internees and undergraduate and post graduate trainees that come from various regions of Pakistan and cultural backgrounds. Fifteen medical student researchers from the CMH-Lahore Medical College and Institute of Dentistry conducted this study as part of a course assignment. These students were in their second year of clinical studies, which means they were non-residents. Ethical approval was obtained from $\mathrm{CMH}-$ Lahore Medical College ethical review committee.

The study used a non-probability convenience sampling strategy. All health professionals employed at CMH between July 2010 and October 2010, who were not temporary employees, were eligible to complete a survey $(\mathrm{n}=200)$. Hospital departments were separated into fifteen groups; each student was responsible to conduct data collection of all departments within their assigned group. Several times a week students distributed surveys to eligible health professionals; interested participants either returned the completed survey to the student researcher or the survey was completed by a structured interview. Students attempted to reach all eligible CMH employees over the 4 months; however, a few were left not interviewed due to unmatched time schedules. All health professionals approached agreed to complete the brief survey.

The survey included 12 questions with pre-established answers and participants had to select their best response from the available options. The survey measured the following: health profession, gender, smoking status, patterns of current use and initiation of those who smoke reasons for quitting, knowledge about hazards related to smoking and secondhand smoke, and perceptions of tobacco control strategies. Survey completion time was less than 15 minutes. A second data source was a review of College and Hospital policies. ${ }^{17}$ Data from completed surveys were analysed using SPSS.

\section{Results}

A total of 152 questionnaires were completed (response rate $=76 \%$ ), which included male doctors $(n=24)$, female doctors $(n=14)$, nursing staff $(n=80)$ and paramedics $(n=34)$. Male respondents totaled 70 $(46 \%)$ whilst $82(53.9 \%)$ were females. A review of the college's policies shows that smoking is totally prohibited in the college, hospital and hostels. This policy is congruent with Pakistan's national ordinance no. LXXIV of 2002 that bans smoking in any place of public work or use. ${ }^{18}$

The rate of ever smokers amongst health professionals is found to be $21 \%$. Table 1 shows the smoking status: $14.5 \%$ of the health professionals are current smokers and $6.6 \%$ were ex-smokers. None of the females reported ever smoking and the rate of ever smokers among the male respondents was $31.4 \%$. Ever smokers' rates among male doctors are $33.3 \%, 8$ out of 24 doctors and all of these were current smokers. Among male paramedical and nursing staff the rate of ever smokers is $52 \%, 24$ out of 46 . Rate of current smokers in members of nursing and paramedical staff is $30.4 \%$ and $22 \%$ of the male members of nursing and paramedical staffs are found as exsmokers.

Table I Smoking status amongst study population

\begin{tabular}{lll}
\hline Status & Frequency & Percent \\
\hline Smoker & 22 & 14.5 \\
Ex-Smoker & 10 & 6.6 \\
Non Smoker & 120 & 78.9 \\
Total & 152 & 100.0 \\
\end{tabular}

In respect to the frequency of smoking, $18.2 \%$ of smokers consumed 15 or more cigarettes on a daily basis. However the majority of smokers, $61.1 \%$ were consuming an average of 1 to 5 cigarettes per day whilst the remaining $20.7 \%$ were smoking between 5-10 cigarettes daily. Hence heavier cigarette smoking is not prevalent. Table 2 shows the geographical distribution of smoking patterns; two of the ever smoker participants did not respond to these items. The most common preference of the ever smokers $(40 \%)$ was to smoke in all places, i.e. their residences, workplaces and public areas, while $20 \%$ indicating preference to smoke at both residence and outdoors.

Table 3 shows the tobacco consumption initiation-age distribution 
among the smokers and ex-smokers. Most smokers and ex-smokers started smoking before 20 years of age $(69 \%)$. The remaining $31 \%$ started between 20 to 30 years of age and there were no individuals who started smoking after the age of 30 . All male doctors who are current smokers started smoking before the age of 20. Majority of the respondents $(53.3 \%)$ reported peer pressure and the fact that their friends smoked. The second leading cause was to help cope with anxiety $(26.7 \%)$ whilst smoking in the family was cited as the least frequent cause at $20 \%$.

Table 2 Geographical distribution of smoking patterns amongst smokers and ex-smokers

\begin{tabular}{lll}
\hline Status & Frequency & Percent \\
\hline Workplace only & 2 & 6.67 \\
Residence only & 4 & 13.33 \\
Outdoor only & 2 & 6.67 \\
Workplace and Outdoor & 4 & 13.33 \\
Residence and Outdoor & 6 & 20 \\
All Places & 12 & 40 \\
Total & 30 & 100 \\
\hline
\end{tabular}

Table 3 Age at which smokers and ex-smokers started smoking

\begin{tabular}{lll}
\hline Age & Frequency & Percent \\
\hline & & \\
$<20$ years & & \\
$20-30$ years & 22 & 69 \\
Total (smokers and ex- & 10 & 31 \\
smokers) & 32 & 100
\end{tabular}

When asked whether they were aware of the ill effects of secondhand smoke on the health of those around them, $27.6 \%$ of health professionals were unaware whilst $72.4 \%$ indicated their awareness. Table 4 shows the response of professionals when they were asked about the most effective anti-smoking strategy. Majority of health professionals thought that health education $(42.1 \%)$ and costlier cigarettes $(19.7 \%)$ constituted the most effective approach. Legislative measures, restrictions and advertisement campaigns garnered $10.5 \%$ each. Only $2.6 \%$ believed that strict warning labels on cigarette packs would be the most effective approach. In regards to whether they believed that increased taxation on the sale of cigarettes was justified, an overwhelming majority (86.2\%) of health professionals replied in the affirmative (Table 5).

Table 4 Opinions on the most effective smoking cessation strategy

\begin{tabular}{lll}
\hline Strategy & Frequency & Percent \\
\hline Health education & 64 & 42 \\
Costly Cigarette & 30 & 20 \\
Advertisement for No-smoking & 16 & 10.5 \\
Punishment & 16 & 10.5 \\
Incentives & 6 & 3.9 \\
Restrictions & 16 & 10.5 \\
Strict Warning labels on packs & 4 & 2.6 \\
Total & 152 & 100
\end{tabular}

When questioned about negative impacts of smoking on health professionals' ability to affectively counsel their patients on the hazards of tobacco consumption and on undertaking smoking cessation programs, the overwhelming majority $(82.9 \%)$ responded in the affirmative. Only a minority (17.1\%) believed that health professionals who smoke are equally effective at imparting antismoking advice as their non-smoking counterparts (Figure 1).

Table 5 Respondents in favor of increased taxation on the purchase of cigarettes

\begin{tabular}{lll}
\hline Response & Frequency & Percentage \\
\hline Yes & 131 & 86.2 \\
No & 21 & 13.8 \\
Total & 152 & 100 \\
\hline
\end{tabular}

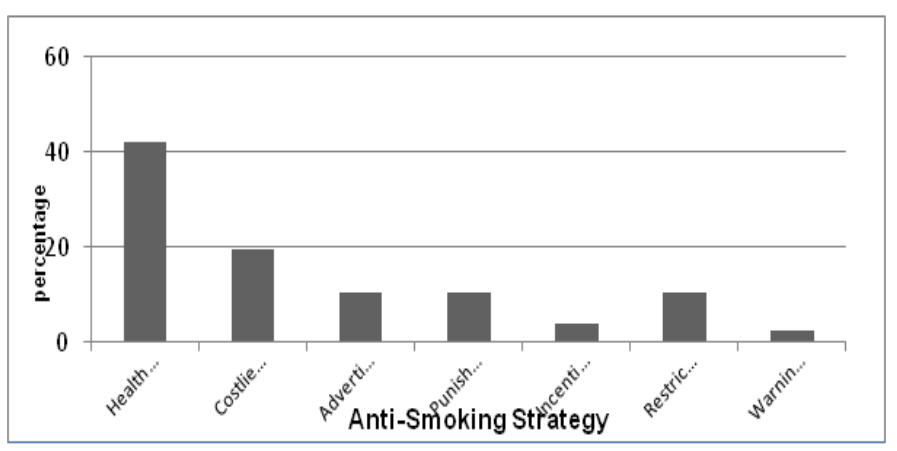

Figure I Effective anti-smoking strategies.

\section{Discussion}

Smoking amongst HPs remains a concern for developing nations like Pakistan. Our study confirms the rates of smoking among health professionals in Pakistan and sheds new light into their views of tobacco control strategies. In our study, smoking rate of current smokers was lower than previously reported at $14.5 \%$. However, when comparing differences in rates among genders and health professional groups, our findings are similar with previous studies. ${ }^{14-16}$ Smoking rates among male health professionals appear to have remained the same at about one third. This is concerning because these health professionals tend to be less effective in treating and counseling tobacco dependence with their patients as compared to their nonsmoking counterparts. ${ }^{19}$ This appears very deceiving for the patient who comes for the advice of smoking cessation when confronted by health professional that smokes. ${ }^{20}$ Productivity concerns are faced by the health care organizations because the quality of service can be affected by the tobacco-related health issues of the employees. ${ }^{21}$ An economic impact assessment of smoking related illnesses amongst health professionals resulting in sick days, medications, consultations, workups, admission charges and impaired employee performance is yet to be adequately assessed.

Our study indicates that $69 \%$ of the smokers and ex-smokers started smoking before their 20th birthday and 31\% started between the ages of 20 and 30 years. Compared to previous studies the trend of initiation age of smoking has shifted to teenage group. ${ }^{15}$ This may be attributable to the development of tobacco industry at a faster pace in the developing nations after a rapid depreciation from the developed nations; ${ }^{22}$ Pakistan has been a focus in the out flourishing and smuggling of cigarettes since $1992-2002 .{ }^{23}$ Also, the neglect of the local authorities in implementing under-age selling bans has been 
observed. ${ }^{24,25}$ Alternately, this finding suggests the need to focus on strategies to address tobacco dependence during health professional education; these students are the health professionals of our future. Enhancing both supports for them to stop smoking and effectively treat their patients who smoke will be important for improving health services for the community. The need for better education was echoed in the study of Asia health professional students. ${ }^{11}$

Novel insights concerning smoking bans and secondhand smoke are revealed by our study results. First only $72.4 \%$ of the health professionals were aware about the ill-effects of secondhand smoke, which suggests a need to enhance education of health professionals. Next college and hospital policy shows a complete smoke-free campus, hospital and hostels, which is in accordance with Pakistani law. ${ }^{17}$ unfortunately, student researchers noted smoking within the hospital when collecting data. Moreover, health professionals who smoke commonly indicated a preference to smoke within buildings (both homes and workplace). This evidence suggests national ordinance is not being enforced, even though policies suggest otherwise. Finally, it is worth noting that only $10.5 \%$ of respondents thought smoking restrictions were an effective tobacco control strategy. We suggest this may indicate a need for stronger educational efforts regarding secondhand smoke exposure and policy parameters.

Health professional respondents of our study thought that health education $(42.1 \%)$ and costlier cigarettes $(19.7 \%)$ constituted the most effective anti-smoking strategy. Cost is also reflected in the belief $(86.2 \%)$ that an increase in taxation on the sale of cigarettes in Pakistan was justified which is in accord with the WHO-FCTC. Affective anti-smoking education strategies at the medical school and training institutions may enhance health professionals efforts and effectiveness with counseling their patients on smoking cessation issues, which echoes previous suggestion made by Asian medical students. ${ }^{11}$ Only $2.6 \%$ of the professionals believed that warning labels on the cigarette packs was an effective anti-smoking strategy; however, in previous studies of 2001 and 2005, warning labels have been considered an effective strategy for reducing tobacco consumption. ${ }^{26,27}$ In Pakistan, warning labels are being published according to the WHO FCTC guidelines. ${ }^{8}$

Consideration of study findings are subject to the following limitations. Given that sampling was non-probability convenience strategy from one hospital, the findings cannot be generalized beyond the study site. In addition, about one quarter of eligible health professionals did not complete a survey, which may indicate a bias representation of eligible health professionals. Given the similarity of smoking rates by gender and health professional group with previous studies, any lack of representativeness is likely not based on smoking status. Beyond this important possible bias, we are unable to comment. Still, the findings from this study affirm some previously reported findings along with provide novel insights to generate new discussion concerning tobacco consumption and control among health professionals in Pakistan.

\section{Conclusion}

Health professionals have an honorable and privileged position in society of caring for the health of their community. Addressing their own addictions, such as tobacco dependence, is of the outmost importance; both for their own health and because personal addictions may hinder their imparting effective health education to patients against smoking. Pakistani national government has implemented appropriate smoke-free laws outlined by the WHO FCTC; unfortunately, the impact of these laws is undermined by lack of enforcement. Education concerning secondhand smoke and its ill effects should be part of the hospital and medical school curriculum because this knowledge could influence support for smoke free environments. Medical students and health professionals training and education of the most recent smoking cessation strategies will be an important step to enhance treatment of tobacco dependence as a health priority by health professionals. Ongoing research focused on smoking rates and views concerning tobacco control among Pakistan health professionals and those working in other low to middle income countries where smoking rates consistently are higher and projected tobacco-related mortality staggering. Evidence of health professionals, who have a central role in treating tobacco dependence, is required to inform health care professional education and tobacco control policy reform.

\section{Acknowledgments}

None.

\section{Conflicts of interest}

The authors declare that there is no conflicts of interest.

\section{References}

1. World Health Organization (WHO). Tobacco Free Initiative (TFI) World Health Organization technical report series, Geneva, 2010.

2. World Health Organization (WHO). Report on the Global Tobacco Epidemic, 2009- Implementing smoke-free environments. World Health Organization technical report series, Geneva, 2009.

3. World Health Organization (WHO). Tuberculosis \& Tobacco orld Health Organization technical report series, Geneva, 2009.

4. Djalalinia S, Tehrani FR, Malekafzali $\mathrm{H}$, et al. Training of general practitioners about smoking cessation counseling. J Pak Med Assoc. 2011;61(5):449-452.

5. Jemal A, Siegel R, Xu J, et al. Cancer statistics, 2010. CA Cancer J Clin. 2010;60(5):277-300.

6. Yusuf S, Hawken S, Ounpuu S, et al. Effect of potentially modifiable risk factors associated with myocardial infarction in 52 countries (the INTERHEART study): case-control study. Lancet. 2004;364(9438): 937-952.

7. Lelong N, Blondel B, Kaminski M. Smoking during pregnancy in France between 1972 to 2003: Results from the national perinatal surveys. J Gynecol Obstet Biol Reprod (Paris). 2011;40(1):42-49.

8. World Health Organization (WHO). Framework Convention on Tobacco Control, updated reprint 2004, 2005. World Health Organization technical report series, Geneva.

9. The Tobacco Atlas. $4^{\text {th }}$ edn, American Cancer Society.

10. World Health Organization (WHO). Progress in tobacco control in Egypt and Pakistan. World Health Organization technical report series, Geneva, 2010.

11. Sreeramareddy CT, Suri S, Menezes RG, et al. Self-reported tobacco smoking practices among medical students and their perceptions towards training about tobacco smoking in medical curricula: A crosssectional, questionnaire survey in Malaysia, India, Pakistan, Nepal, and Bangladesh. Subst Abuse Treat Prev Policy. 2010;16(5):29.

12. Nawaz H, Imam SZ, Zubairi AB, et al. Smoking habits and beliefs of future physicians of Pakistan. Int $J$ Tuberc Lung Dis. 2007;11(8):915-919. 
13. Karamat A, Arif N, Malik AK, et al. Cigarette smoking and medical students at King Edward Medical University, Lahore (Pakistan). J Pak Med Assoc. 2011;61(5):509-512.

14. Piryani RM, Rizvi N. Smoking habits amongst house physicians working at Jinnah Postgraduate Medical Center, Karachi, Pakistan. Trop Doct. 2004;34(1):44-45.

15. Chaudhry MA, Chaudhry IA, Ur-Rahman M. Prevalence of smoking among health care providers in tertiary care hospitals. Rawal Medical Journal. 2009;34(1):40-42.

16. Malik AK, Chaudhry A, Karamat A, et al. Cigarette smoking and health care professionals at Mayo Hospital, Lahore, Pakistan. J Pak Med Assoc. 2010;60(6):509-512.

17. Code of Conduct, CMH-Lahore Medical College, Lahore.

18. The Gazette of Pakistan Ordinance no. LXXIV of 2002 An ordinance to provide for prohibition of smoking and other tobacco uses in places of public work or use and public service vehicles and to protect the health of non-smokers.

19. Tong EK, Strouse R, Hall J, et al. National survey of U.S. health professionals' smoking prevalence, cessation practices, and beliefs. Nicotine \& Tobacco Research (Oxford). 2010;12(7):724-733.
20. Ayad, Jindeel MD. Health Care Providers Who Smoke. American Journal of Nursing. 2010;110(6):11.

21. Babcock P. Sept 2007 Helping workers kick the habit: programs aimed at helping employees give up tobacco can pay off in lower health care costs... reprinted with permission. HR Magazine. Journal of the Association of Occupational Health Professionals in Healthcare. 2008;28(1):35-37.

22. Eriksen M, Mackay J, Ross H. The Tobacco Atlas ( $4^{\text {th }}$ edn).

23. World Health Organization (WHO). Tobacco industry activities in Pakistan 1992-2002. World Health Organization technical report series, Geneva, 2010.

24. Daily Times: Sale of tobacco to minors continues, March $29^{\text {th }} 2012$.

25. The Nation: Rampant ads beat back anti-tobacco efforts. May $23^{\text {th }} 2012$.

26. Strahan EJ, White K, Fong GT, et al. Enhancing the effectiveness of tobacco package warning labels: a social psychological perspective. Tob Control. 2002;11(3):183-190.

27. Hammond D, Fong GT, McNeill A, et al. Effectiveness of cigarette warning labels in informing smokers about the risks of smoking: findings from the International Tobacco Control (ITC) Four Country Survey. Tob Control. 2006;15(suppl III):iii19-iii25. 